Winter Meeting, 8-9 December 2015, Roles of sleep and circadian rhythms in the origin and nutritional management of obesity and metabolic disease

\title{
Postpartum weight retention and sleep: a systematic review
}

\author{
L. Alrefaai, G.TH. Ellison, G.R. Law and E.M. Scott \\ Temporal Influences on Metabolic Events (TIME) Research Group, The Sound Asleep Laboratory, Leeds Institute of \\ Cardiovascular and Metabolic Medicine (LICAMM), University of Leeds, Leeds LS2 9JT
}

Various studies have shown that short sleep duration is associated with higher body weight and a greater risk of obesity. It is unclear whether disrupted sleep in the postpartum period has a similar impact on women's weight. The aim of the present study was to systematically review the available evidence for an association between sleep and postpartum weight retention. EMBASE, Medline and CINAHL were searched for studies published from 1946 to May 2015. Search results were manually scrutinised for any relevant studies. Relevant articles found were also screened through forward and backward citation to look for all possible studies to include.

A total of $n=9$ studies were found using a variety of designs, various subjective measures of sleep, assessed across a range of different time points postpartum, and using different cut-off points for what was considered "substantial" weight retention. Of these studies: $\mathrm{n}=4$ found a significant association between short sleep duration and postpartum weight retention; $\mathrm{n}=1$ found a linear association between body weight and sleep duration; while $n=4$ studies found no evidence of an association between disrupted sleep and postpartum weight retention.

\begin{tabular}{|c|c|c|c|}
\hline Author, year & Country & $\mathrm{N}$ & Studies results \\
\hline Gunderson et al., $2008^{(1)}$ & USA & 865 & $\begin{array}{l}\leqslant 5 \mathrm{hrs} / \text { day sleep at } 6 \text { months postpartum is associated with an odds of } 3.13 \text { (95\%CI: } 1.42-6 \cdot 94) \\
\text { for retaining } 5 \mathrm{~kg} \text { or more compared to women who sleep } \geqslant 7 \mathrm{hrs} / \text { day. }\end{array}$ \\
\hline Siega-Riz et al., $2010^{(2)}$ & USA & 688 & $\begin{array}{l}\leqslant 5 \mathrm{hrs} / \text { day sleep at } 3 \text { months postpartum is associated with a risk ratio of } 1.9 \text { (95\%CI: } 1.5-2 \cdot 4) \\
\text { for retaining } \sim 4.5 \mathrm{~kg} \text { compared to women who sleep } \geqslant 8 \mathrm{hrs} / \text { day. }\end{array}$ \\
\hline Althuizen et al., $2011^{(3)}$ & Netherlands & 118 & $\begin{array}{l}\text { The coefficient estimate }(\beta) \text { of the relationship between sleep duration and absolute weight } \\
\text { change at } 6 \text { weeks, } 6 \text { months and } 12 \text { months postpartum was }-0.53 \mathrm{~kg} / \mathrm{hr} \text { of sleep }(95 \% \mathrm{CI}:-1.08-0.02)\end{array}$ \\
\hline Taveras et al., $2011^{(4)}$ & USA & 560 & $\begin{array}{l}\text { The coefficient estimate }(\beta) \text { of the relationship between } \leqslant 5 \text { hrs/day sleep at } 6 \text { months } \\
\text { postpartum and postpartum weight retention at } 3 \text { years postpartum was } 1.44 \mathrm{~kg}(95 \% \mathrm{CI}: 0.02-2 \cdot 86) \text {. }\end{array}$ \\
\hline
\end{tabular}

As such, studies published to-date provides only equivocal and inconsistent results regarding the association between sleep and postpartum weight retention. This review indicates the need for more robust research in this area using, in particular, more consistent prospective designs, with better quantification of weight retention and validated instruments for the subjective assessment of sleep (or, better still, objective measurement of sleep duration).

1. Gunderson EP, Rifas-Shiman SL, Oken E et al. (2008) Association of Fewer Hours of Sleep at 6 Months Postpartum with Substantial Weight Retention at 1 Year Postpartum. Am Journal Epidemiol 167, 178-87.

2. Siega-Riz AM, Herring AH, Carrier K et al. (2010) Sociodemographic, Perinatal, Behavioral, and Psychosocial Predictors of Weight Retention at 3 and 12 Months Postpartum. Obesity 10, 1996-2003.

3. Althuizen E, van Poppel MN, de Vries JH et al. (2011) Postpartum behaviour as predictor of weight change from before pregnancy to one year postpartum. BMC Pub Hlth 11, 165.

4. Taveras EM, Rifas-Shiman SL, Rich-Edwards JW et al. (2011) Association of Maternal Short Sleep Duration with Adiposity and Cardiometabolic Status at 3 Years Postpartum. Obesity 1, 171-178. 